\title{
Accessing medical equipment in developing countries through remanufacturing
}

\author{
Solomon Eze ${ }^{1}$ (D) $\cdot$ Winifred ljomah ${ }^{1} \cdot$ Tse Chiu Wong $^{1}$
}

Received: 11 August 2018 / Accepted: 13 December 2018 / Published online: 4 January 2019

(C) The Author(s) 2018

\begin{abstract}
While many developing countries may not afford state-of-the-art medical equipment, they may take advantage of the significant price reduction and other benefits of remanufacturing to solve their perennial healthcare problems that are aggravated by the shortage of medical equipment. As a first step towards implementing medical equipment remanufacturing in developing countries, the regulatory perspectives which plays a crucial role in the industry should be understood. However, since regulation of medical equipment is weak or inexistent in most developing countries, the regulatory perspectives with respect to remanufacturing or related activities in both the European Union (EU) and the United States of America (US) are first examined to determine their impacts. Unfortunately, there appears to be a lack of precise definition of remanufacturing for medical devices. An unambiguous definition is necessary to promote effective research, improve understanding, ensure uniformity of standards, drive quacks out of the remanufacturing market and thus, enhance customer confidence in remanufactured products. This paper proposes a definition for medical equipment remanufacture. The principal advantage of this definition is that it could be adopted in future research toward increasing access to functional medical equipment to developing countries through remanufacturing.
\end{abstract}

Keywords Medical device remanufacturing $\cdot$ Medical equipment remanufacturing $\cdot$ Medical devices for developing countries $\cdot$ Medical equipment for developing countries

Solomon Eze

Solomon.eze@ strath.ac.uk

Winifred Ijomah

w.I.ijomah@strath.ac.uk

Tse Chiu Wong

andy.wong@strath.ac.uk

1 Design, Manufacture and Engineering Management, University of Strathclyde, Glasgow, Scotland 


\section{Introduction}

It is difficult for many developing countries to access medical equipment necessary for healthcare. This impacts their capability to diagnose, prevent, monitor or treat diseases and injuries. This challenge is gruesome considering that majority of the world's population reside in developing countries where this acute shortage of functional medical equipment is experienced the most. Consequently, developing countries are characterised by high mortality rates over conditions that could be treated or monitored successfully if the necessary resources and technologies such as were available. Figures $1 \mathrm{a}$ and $\mathrm{b}$ retrieved from [1] show the top causes of

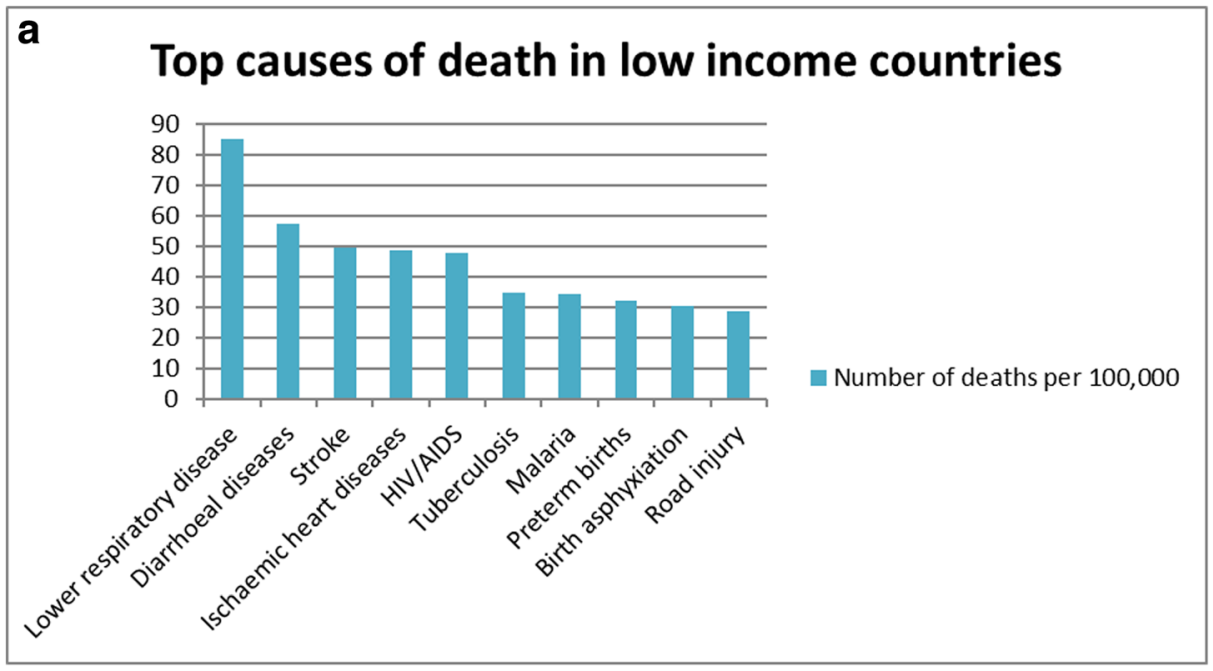

\section{b Top causes of death in high income countries}

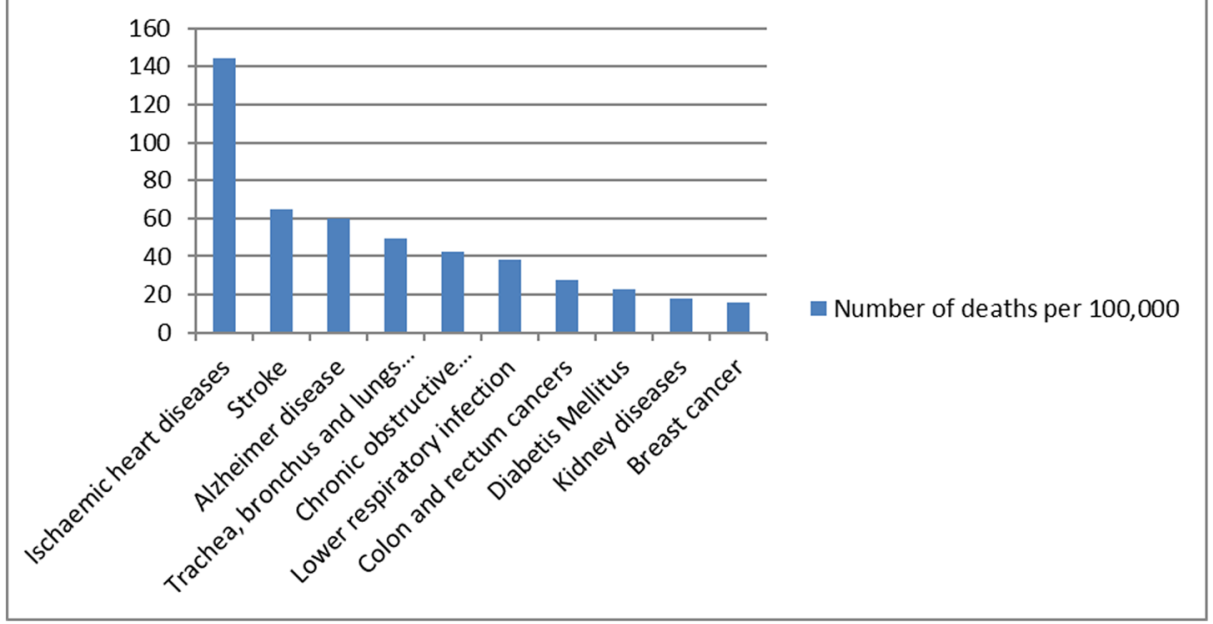

Fig. 1 Top causes of death in high low-income (a) and high income (b) countries in 2015. Many causes of death in low-income countries do not constitute a significant healthcare challenge to high-income countries. These conditions would be manageable if the right resources such as medical equipment are available 
death in both developing and developed countries in 2015. Apart from Ischaemic heart diseases, stroke, and lower respiratory diseases, other top causes of death in developing countries are now insignificant problems for developed countries.

This inadequate access to medical equipment in developing countries has attracted global interest $[2,3]$. Consequently, many organisations in developed countries provide medical equipment as donations to them, to help alleviate the problem. However, a significant portion of donated medical equipment becomes unserviceable on arrival and/or after brief use [4]. Repair is also, often difficult because OEM's technical support is usually already spent by the time a medical equipment is shipped to developing countries either as a donation or as a used product [5].

Some scholars suggest designing low-cost medical equipment for developing countries to increase affordability [6,7], while others question the appropriateness of low-cost medical devices in terms of reliability and effectiveness [8]; the reason being that what constitutes a reliable technology may require more research and development and hence, be more expensive products to deliver. Investing in developing countries market may however, not be very appealing to many original equipment manufacturers (OEMs) who already have only nominal interest in the market; believing they can only make a minimal return on their investment from it $[9,10]$.

Remanufacturing seems to be an attractive solution to this challenge since it is based on used equipment and components that would ordinarily be discarded. It can potentially provide a basis for many OEMs to become interested in developing countries' medical equipment markets since it would afford an opportunity to make profits from many equipment bound for disposal in developed countries. Also, it can increase the service life of medical equipment, correspondingly extending the duration over which returns on investments can be achieved. In addition, implementing medical equipment remanufacturing in a developing country setting would provide employment, increase the knowledge of medical technology among the people and thus, provide a sustainable supply of skilled personnel for the healthcare industry.

The three main players in the medical equipment lifecycle are the manufacturers, the regulators and the users [11]. Manufacturers usually aim to understand the health care needs of the users in order to design and develop medical equipment that would address them. However, the medical equipment would not be allowed entry into a country's market or to the users unless regulators confirm that they have been designed and produced according to appropriate quality standards and that they would be safe and effective. Regulation is therefore a primary deciding factor in the medical equipment market that would potentially affect the implementation of medical equipment remanufacturing. Since medical equipment regulation is weak or inexistent in many developing countries, this paper will instead, examine the perspectives of the US and EU regulations with respect to medical equipment remanufacturing or related practices in order to learn from them. Secondly, it would propose a working definition of medical equipment remanufacturing for the purpose of increasing access to quality medical equipment in developing and interested developed countries.

\section{Definitions of medical device}

There are several ways to define a medical device. Most popular definitions are from the EU medical device directive and the US Food and Drug Administration (FDA). Each definition attempts to capture the roles of the numerous devices used in healthcare and so, appears lengthy. However, medical devices may be briefly defined as any apparatus, software, material, 
or other similar or related item intended to be used in diagnosing, preventing, monitoring, treating, or alleviating a disease [12]. The term 'disease' encompasses all unfavourable health changes, including injuries and mental health.

Medical devices include about one million five hundred thousand different devices in over ten thousand generic groups available for healthcare worldwide; ranging from complex capital-intensive devices with significant financial value to common devices such as thermometers, software, and invitro reagents. It is therefore a challenge to precisely capture all medical device types using one classification system. In practice, several classifications exist for medical devices. Typical classifications are based on the following considerations [12]:

- Acquisition: Prescribed or over-the-counter

- Number of utilisation as single-use devices (SUDs) and reusable devices,

- Stage of healthcare that they are used to deliver as preventive, diagnostic, therapeutic, and assistive/rehabilitative devices,

- Type of use: general and disease-specific

- Risk: Classes I, IIa, IIb, and III in the UK and classes I, II, and III in the US. In these countries, this classification is used to determine the market entrance requirement of a given medical device.

SUDs refer to devices recommended to be used once on one patient; on a single procedure [13] while reusable devices can be reused on same or other patients after various levels of disinfection. In practice, a reusable medical device may be capital or non-capital. Reusable capital medical devices usually have greater design maturity and are not implantable. Both reusable medical devices and SUDs may be diagnostic, therapeutic, preventive or assistive/ rehabilitative or life-supporting in nature. However, only reusable capital medical devices also known as medical equipment [2] are included in the maintenance management programme of health care institutions. Since medical equipment are a subset of medical devices, both terms will be used interchangeably in this paper. However, the more expensive devices or equipment will likely provide the necessary economic justification for remanufacture.

\section{Medical equipment remanufacturing literature}

Medical equipment differ from products in other sectors because of their extreme safety requirements. They operate directly on human beings unlike the other products which are only controlled and/or operated by humans. For industrial or automotive equipment; degradation alone may only result in loss of quality until a critical component fails. For these products, safety issues usually result when a combination of failures occur such as when a major component failure is accompanied by the failure of an alarm or warning system that sends the signal to the user. In contrast, degradation of medical equipment, as well as its failure, usually causes safety issues to the user or patient. The issues may be in the form of overdose, electrocution or overexposure to radiation all of which can be catastrophic and may even cost a patient's life. Medical device directives and regulations in different countries are constituted to avoid such occurrences; ensuring that patients and healthcare institutions have access to quality medical equipment. Thus, remanufacturers of medical equipment should also demonstrate that their products are safe and effective to comply with existing regulations.

There is a paucity of information on medical equipment remanufacturing practice. D'Adamo [14] evaluated top management's commitment across several industries including 
medical equipment manufacturers to determine their disposition concerning incorporating remanufacturing in their business. The authors used SWOT AHP studies to develop useful insights to enhance decision to implement remanufacturing. Widera and Seliger [15] used business model canvass to address profitability issues associated with remanufacturing using an insulin pump manufacturer as a case study. The authors demonstrated that product service systems could be used advantageously to increase the profitability of remanufacturing.

A closed loop supply chain involving as case study, a medical equipment manufacturer who also engages in remanufacturing and supplies to a single retailer is considered in [16]. Deterministic relations for optimal product pricing and profit were derived for the manufacturer. The analysis assumes that the market demand is a linear function of the retail price which decreases with increases in price. Sloan [17] developed safety cost trade-offs to inform singleuse medical device re-use using Markov decision process model. The model is primarily useful in resolving ethical, liability, environmental and cost issues associated with reusing single-use medical devices.

While these papers address medical equipment remanufacturing from various perspectives, none has reported the manner in which it is practised in the industry, especially from the perspective of fulfilling regulatory requirements which determine medical equipment market entry. This paper therefore, intends to analyse the EU and US regulatory perspectives with respect to medical equipment remanufacturing or related practices and to propose a definition for remanufacturing which can help to achieve the goal of increasing access to functional medical equipment in developing countries. This is particularly important as current approaches are unsustainable. For instance, the European remanufacturing network market studies show that many developing countries are destinations for used medical equipment sold 'as is' or following poorly conducted recovery process [18], a situation which has contributed to the abundance of poor quality medical equipment that either cannot be put to use or would no longer be safe.

\section{Methods}

A qualitative approach was adopted for this research with data sourced from the literature and from original medical equipment manufacturers' (OEM) websites. Initially, a literature search was performed on Scopus using the keywords "Remanufactur*" AND ("Medical equipment" OR "Medical device*") with the aim of retrieving information on publications relating to remanufacturing in the medical device sector and establishing the research gaps. Grey literature search was then performed to gather information on the regulation of activities relating to remanufacturing in both the US and EU. The positions of the two regulations regarding remanufacturing or related activities were analysed against the conventional definition of remanufacturing in [19-23]. Further, data on OEM refurbishment of medical imaging equipment were extracted from the European Remanufacturing Network's market report [18]. This is because the OEM refurbishment practice was found to be similar in many aspects, to remanufacturing especially with respect to addressing medical equipment challenges facing developing countries. The data highlight the similarity of the involved processes which follow popular recommendations of the EU Radiology and IT professionals with the conventional definition of remanufacturing. Based on the findings and the peculiarities of developing countries, a working definition of medical equipment remanufacturing is proposed which is believed to better position remanufacturing towards providing a sustainable solution to the 
shortage of medical equipment in developing countries. The proposed definition was finally, improved upon and validated by experts selected from developing countries health care industry.

\section{Regulatory perspectives in relation to medical equipment remanufacturing}

Activities viewed as remanufacturing from the perspectives of the EU medical device directives and US Federal Drug and Cosmetics Act are presented in "Regulation of secondary market activities related to medical device remanufacturing in the EU and US" section. "Analysis of regulatory perspectives relating to medical equipment remanufacturing" section analyses these perspectives relating to medical equipment remanufacturing and gives recommendations. "Proposing a new definition for medical equipment remanufacture" section proposes a definition for medical equipment remanufacturing while subsequent sections validate the definition and suggest recommendations for implementing medical equipment remanufacturing.

\section{Regulation of secondary market activities related to medical device remanufacturing in the EU and US}

The Centre for devices and radiological health of the Food and Drug Administration (FDA) regulates the medical device market in the US while the competent authority in each EU state performs the role according to the provisions of the Medical device directive 93/42/EEC, Directive 90/385/EEC on active implantable medical devices which are amended to Directive 2007/47/EC and Directive 98/79/EC on in-vitro diagnostic medical devices. The competent authority reports to the minister of health and ensures that the content of medical device directives are correctly integrated into the national law and properly applied to grant qualified medical devices access to the EU market [19]. The competent authority in the UK is the Medicines and Healthcare Products Regulatory Agency (MHRA). In the EU, the Directives require manufacturers to declare the conformity of their class I devices. For other classes of medical devices, a designated independent body or notified body in the state assesses the conformity of the products before placing them on the market. Similarly, while general and special controls apply to class II and class III medical devices in the US, only the general controls apply to class I devices.

There is no mention of the term 'remanufacturing' in the EU medical device directives (MDD). The closest term to remanufacturing in the directives is 'full refurbishment' of medical equipment which is for this reason, considered in this paper. A medical equipment is fully refurbished if it is completely rebuilt or made 'as new' from existing equipment with the addition of new parts and with a new useful life assigned to the resultant product so that the resultant product is reintroduced to the market in the name of the entity that performed the full refurbishment [24]. The act of "placing on the market" for a fee, from another user consummates medical equipment full refurbishment. The entity that performs full refurbishment according to the directive has the same obligations as a manufacturer in the appropriate EU device directives. Such operators are therefore required to satisfy the same conditions expected of manufacturers such as quality systems management and declare the conformity of their products with appropriate directives by applying for and affixing a CE marking on them. It is essential to remark that fully refurbished medical equipment is based on used equipment which 
is adequately restored and then placed on the market for sale, hire or use by a different user. Figure 2 summarises the processes of the EU MDD with respect to full refurbishment. As shown, the first stage is apparently the same as remanufacturing as long as replacement parts are identical to the replaced parts such that the intended use of the resultant product is sustained. The second stage represents the operator's intention which is to re-identify the device in its name before placing it on the market in stage 3.

In the US, the FDA defines remanufacturing as the processing, conditioning, renovating, repackaging, restoring, or any other act that significantly changes a finished device's performance or safety specifications, or intended use [25]. Although relatively less strict, this definition attempts to accommodate all the end-of-life processes in the medical device sector such as reprocessing of single use and multiple use devices. FDA-defined remanufacturers are required to have their products approved by fulfilling the requirements of section $510(\mathrm{k})$ of the Federal drug and cosmetics (FD\&C) Act or through the premarket approval (PMA) because their operation would significantly change the performance and/or safety specification of the original products. In fact, the main emphasis in the FDA's definition of remanufacturing is "significantly changes a finished device's performance or safety specification." The $510(\mathrm{k})$ route requires the manufacturers or FDA-defined remanufacturers to demonstrate that the device is at least, as substantially safe and effective as a marketed equivalent in the US. PMA, on the other hand, is the most stringent approval route required by the FDA for devices that do not have an existing equivalent or predicate in the US market [26]. The FDA grants it following the examination of scientific evidence such as randomised clinical trials (RCT) demonstrating the device's safety and effectiveness [27]. There is however, no regulation currently, for activities such as repair and refurbishment that are not regarded to change a finished product's performance or safety specification. Figure 3 summarises the FDA position on remanufacturing and these other activities.

According to Parkinson and Thompson [28], reprocessing includes both refurbishment and remanufacturing. The EU medical device directives do not approve SUD reprocessing due to

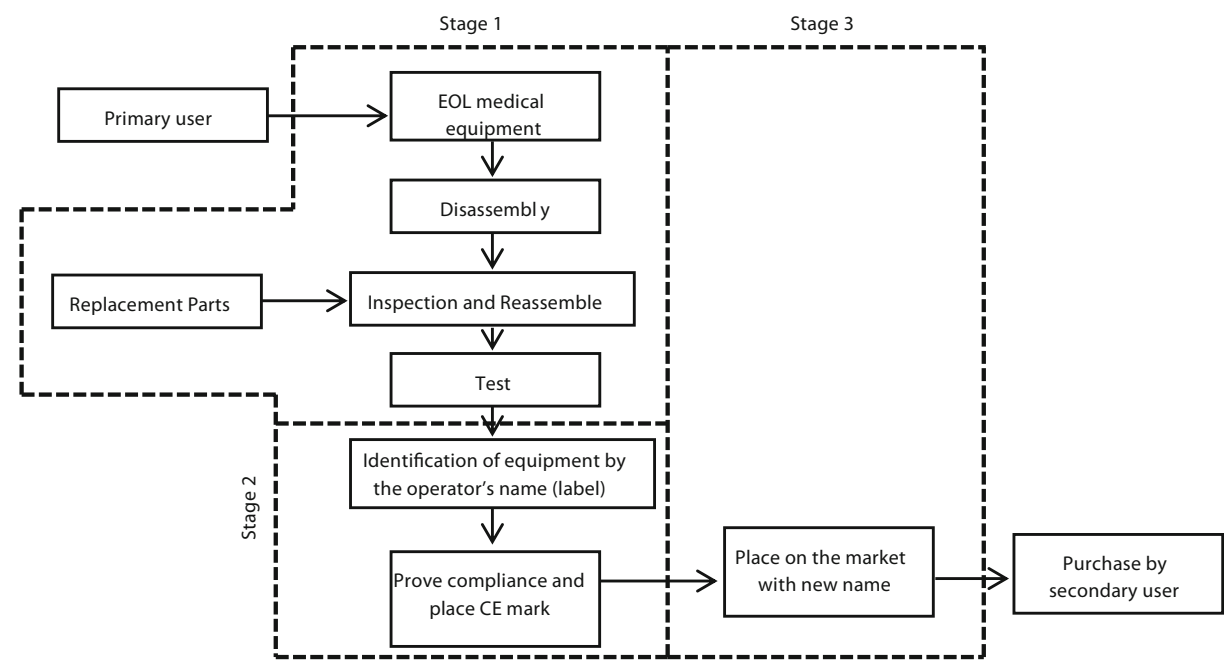

Fig. 2 Schematic diagram showing the process of full refurbishment as portrayed in the EU MDDs 2007/42/EC and 98/79/EC. The first stage is apparently the same as remanufacturing as long as replacement parts are identical to the replaced parts such that the intended use of the resultant product is sustained. The second stage represents the operator's intention which is to re-identify the device in its name before placing it on the market in stage 3 


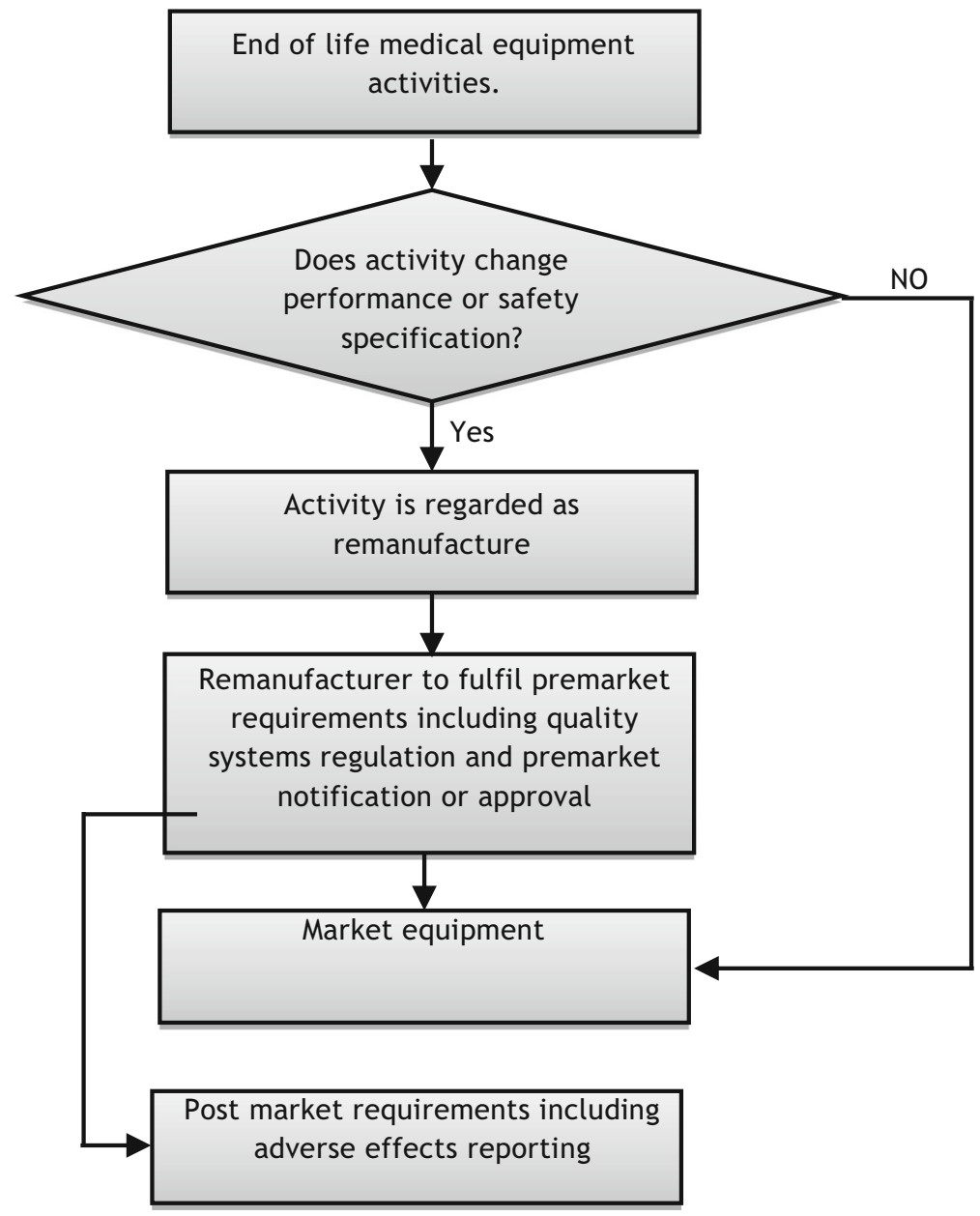

Fig. 3 Flow chart describing FDA's end of life medical equipment activities. Currently, FDA does not have any regulations exist operators in this category

safety and quality concerns. Anyone that reprocesses a device or remanufactures it would therefore, accept the full legal responsibility of a manufacturer. The MHRA distinguishes SUD remanufacture from reprocessing and released guidelines for potential remanufacturers which explicitly regards them as manufacturers. The guideline also requires them to operate in closed loop supply arrangement with partnering healthcare institutions. According to the MHRA, the operators are to both demonstrate that their products are fit for the EU market just like manufacturers of new medical equipment and accept to be liable in case of any adverse incidents arising from using their finished products [29]. Reprocessing however, represents a broad range of activities some of which include simple cleaning, various levels of disinfection or sterilisation and/or repackaging with or without disassembly. Sterilisation is the highest level of disinfection which aims at killing all the microorganisms present in a component using physical, chemical or physiochemical means. It is distinct from cleaning and usually introduces several quality and safety issues as the number of reprocessing cycle increases. For instance, Tessarolo [30] found that the physicochemical Nano-scale etching of electrophysiology catheter shaft sterilised with 
hydrogen peroxide gas plasma increased with the number of reprocessing cycles. Similarly, Lee [31] noted that deep cracks and deposit of contaminants begin to occur if an endoscope is reprocessed up to five times. Thus, reprocessing of medical devices can cause loss of colour, material degradation such as cracking and chemical change while residual sterilising agent may cause toxic effects if they make contact with patients [32]. Despite these observations, the reprocessing of SUDs appears to be gaining greater support both in the developed and developing countries. However, in developed countries, only expensive SUDs are reprocessed while developing countries reprocess even inexpensive SUDs to save cost [33, 34].

The main reasons why SUD reprocessing is becoming popular include the following:

- Economic reasons as some single-use devices are costly and several may be used in a single procedure. For instance, an ultrasound catheter costs up to 5000 US dollar [35]

- The belief that some devices are just labelled as SUDs by manufacturers who would profit if hospitals replace rather than reuse them [3, 19].

- To reduce environmental pollution and cost of safe disposal of medical wastes [35, 36].

- Regulators such as the FDA grant premarket approval to OEMs based on the intended use of their devices. OEMs however, simply label their devices SUD because they do not wish to carry out studies to show that the devices can be reused. Moreover, OEMs of some reusable products often relabel the products SUD without changing the design significantly [13]

- FDA finds no reasonable evidence that reprocessing and reuse of single-use devices result in increased risk of cross-infection [36, 37].

- Some OEMs such as Stryker and Medline currently offer reprocessed SUDs as part of their overall corporate offering [38].

To correctly apply remanufacturing, it would be necessary to determine what constitutes remanufacturing in relation to SUDs and whether existing practice within the reprocessing industry can be regarded as remanufacturing or amended to comply with remanufacturing requirements. One way of achieving this may be to make the guidelines process-dependent while specifying necessary quality system requirements.

More than the developed world, SUD reprocessing and remanufacturing of medical devices would be more beneficial to developing countries given their poor socioeconomic reality and technological advancement. However, many developing countries do not yet have sufficient regulatory framework in place, to monitor both SUD reprocessing and remanufacture to ensure that resultant products would be safe and effective [13,33].

\section{Analysis of regulatory perspectives relating to medical equipment remanufacturing}

The three essential components of full refurbishment include: 1) Activities involved in adequately restoring the used medical equipment, 2) Re-identification of the product to reflect the full refurbisher's identity, 3) Placing the medical equipment on the market in the name of the entity that carried out the full refurbishment. As full refurbishment is said to alter the intended use of the medical device, the fully refurbished device is regarded a newly manufactured from regulatory perspective and therefore, subject to the appropriate device directives.

In the US, FDA-defined remanufacturers are also required to abide by the quality systems (QS) regulation which is the current good manufacturing practice (CGMP) [5, 39]. Remanufacturers according to the FDA include those reprocessing of single-use medical devices, a process which in FDA's assessment, alters the intended use of a medical device by changing it 
from single-use to multiple-use device [39]. In addition to implementing QS regulations, FDAdefined remanufacturers are required to follow the designated routes of premarket notification or premarket approval to introduce their products to the market. The FDA's definition does not provide a basis for deciding whether a device is remanufacturable. It fails to recognise that all medical devices are not remanufacturable. Technically, a product is remanufacturable if it has a core which is disassemblable, with the possibility of thorough cleaning, inspection, replacement/repair of damaged components such that the resultant product becomes at least, as good as new with matching or better warranty [19, 21-23]. Remanufacturing is thus, a restorative strategy. Medical equipment remanufacturing should therefore, be viewed from that perspective and every ineligible device deemed unfit for remanufacture.

Lack of clear definition for remanufacturing has been cited as a major challenge to the growth of the remanufacturing industry [21]. In the EU, the term "remanufacturing" has not used at all in the medical device regulatory framework and so, provides no guide for potential remanufacturers. Similarly, the FDA-defined remanufacturing which covers a broad range of processes does not emphasise the important activities such as disassembly, inspection, and reassembly that characterise remanufacturing. Remanufacturing in the medical device industry thus suffers from the unspecific definition by the FDA and the absence of a definition in the EU medical device directives. This multiplicity of terminology and definitions may be implicated in the absence of substantial evidence in the literature, of the practice of remanufacturing as defined by the FDA or full refurbishment as defined in the EU medical device directive. On the contrary, refurbishment according to the green paper on Good Refurbishment Practice (GRP) of medical equipment proposed by the European Coordination Committee of the Radiological, Electro-medical and Healthcare IT Industry (COCIR) abounds in the literature and is mostly carried out by OEMs. Table 1 compares FDA-defined remanufacturing, Full refurbishment and COCIR's GRP with critical components in the conventional definition of remanufacturing while Table 2 summarises the GRP refurbishment activities of four major original medical equipment manufacturers as adapted from $[18,43]$ and the respective OEMs websites.

\section{The good refurbishment practice (GRP)}

GRP was developed to standardise the refurbishment of medical imaging equipment to distinguish them from conventionally refurbished, repaired or used equivalents sold "as is" as permitted by both the EU medical device directives and by the U.S FDA [11, 24]. The GRP aims to optimise conventional refurbishment which does not involve extensive work [28] and "same as new" warranty [19] that are necessary to boost the customers' confidence in the product. Thus, medical imaging equipment refurbished according to the GRP guideline would have high degree of safety and quality as with new equivalents. Thus, refurbishment according to GRP guideline yields "as good as new" imaging equipment with warranty equivalent to that of equivalent new products. There are no premarket qualification costs associated with GRP since it does not claim to change the products. Thus, GRP has cost-saving advantages. COCIR sets the following criteria for determining the suitability of medical equipment for refurbishing [44]:

- Intended use and product specification - This implies that GRP only intends to make the equipment available to perform as originally intended when it was first introduced in the market. For instance, GRP cannot be performed on a single-use device since it was originally intended for a single use. 


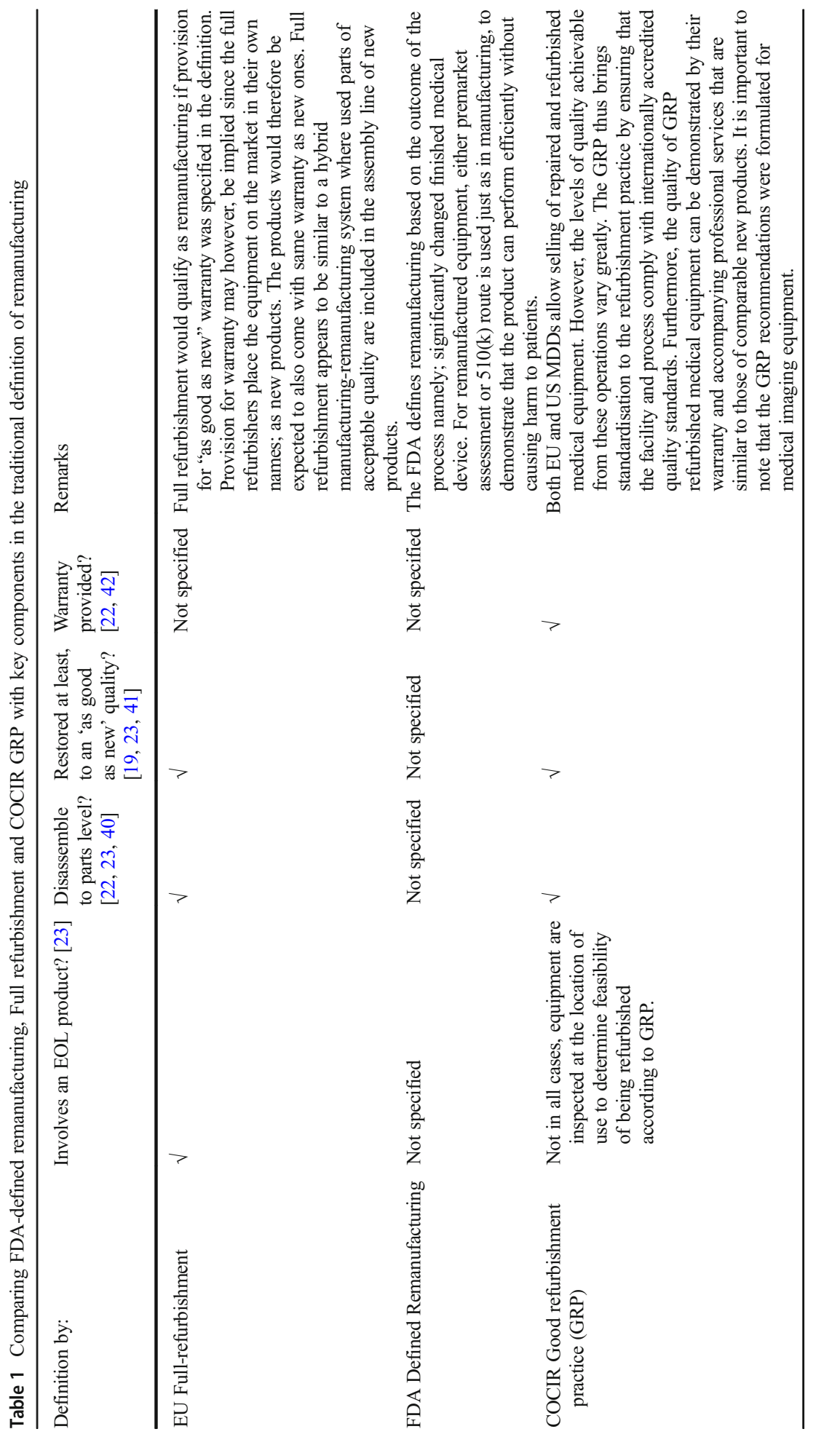




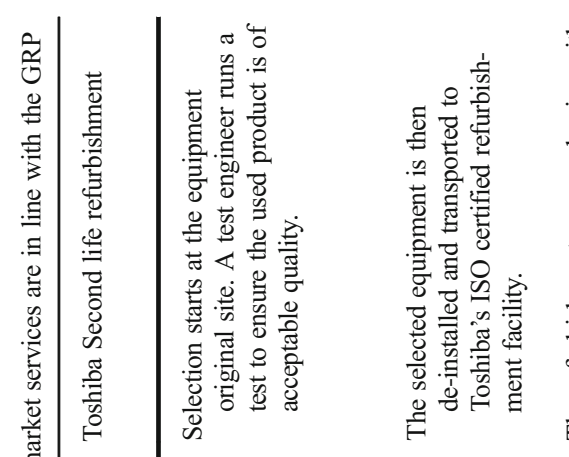

言= 营

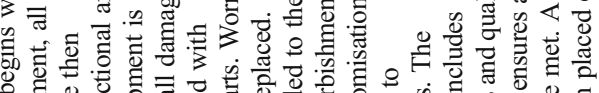

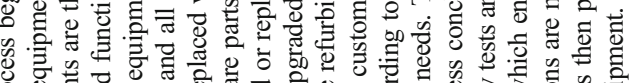

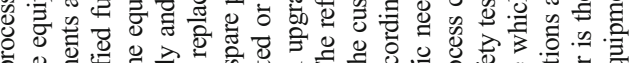

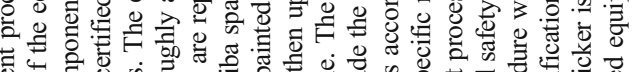

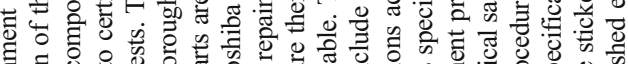

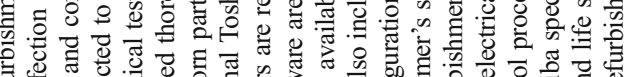

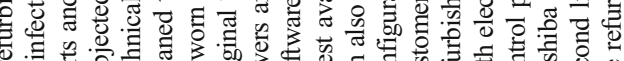

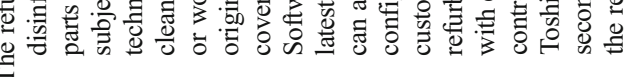

亨

उ

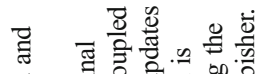

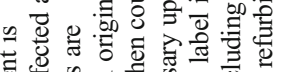

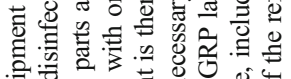

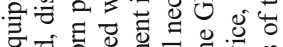

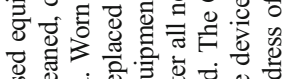

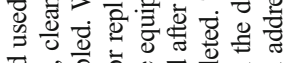

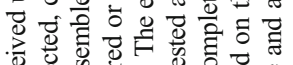

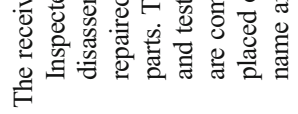

遌递

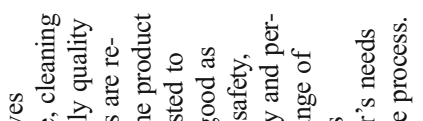

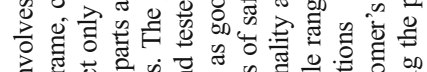

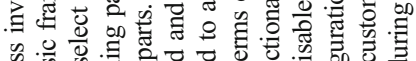

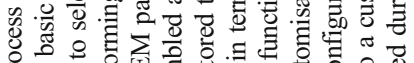

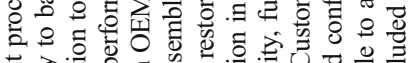

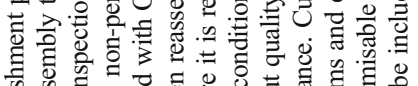

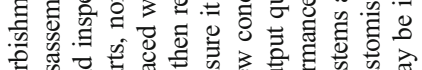

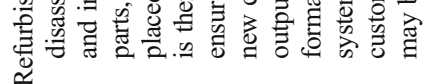

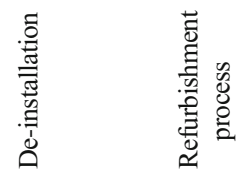




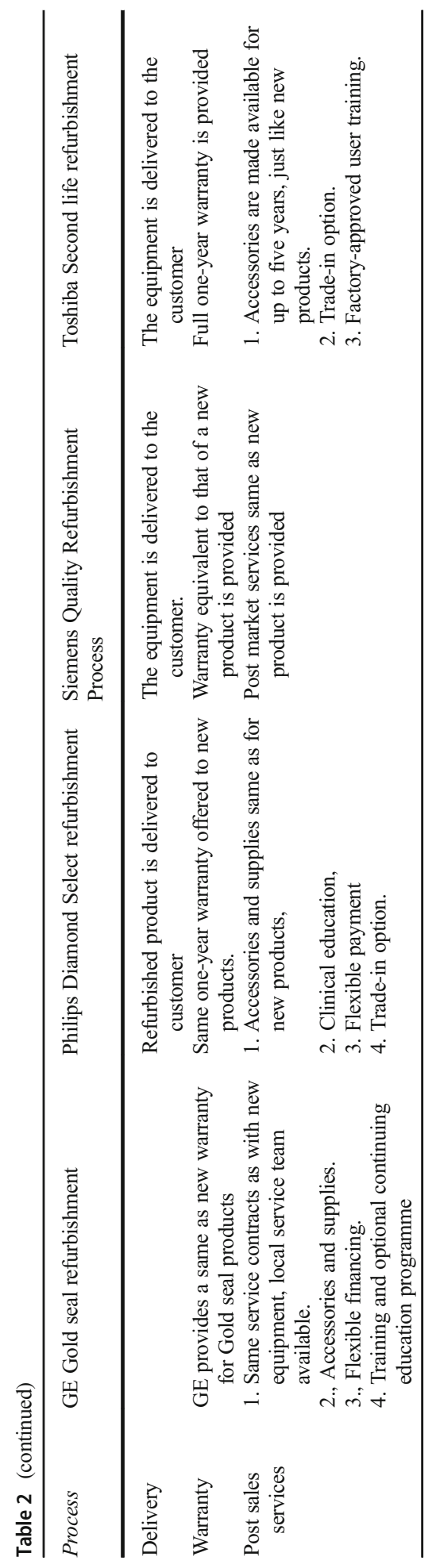


- Satisfy same standards as at the time of first placement - A medical equipment to be refurbished according to the GRP must either be operating within the required medical equipment standards at the time of its selection for refurbishing or can be restored to that standard through refurbishing.

- Have significant residual lifetime and serviceability - A medical equipment to be refurbished in line with the GRP must have ample residual life. A significant residual life is essential to guarantee profitability and quality of the resultant product.

GRP guideline contains a clear standard operational procedure for vendors that refurbish medical equipment; making sure the activity is performed in environments similar to those of OEMs and that the warranty specified is same as for new equivalent product. According to COCIR, GRP is performed by organisations that can demonstrate required levels of i) quality management, ii) resource management iii) production and service provisions, iv) capability to control nonconforming product and conduct post sales surveillance v) validation documentation, labeling of refurbished equipment as "refurbished", and supplier management process. It is important to note that the labeling does not take away the OEM's identity from the refurbished equipment.

\section{Proposing a new definition for medical equipment remanufacture}

The EU's definition of full refurbishment would have the same meaning with conventional remanufacturing if it specified "as good as new" warranty for the resultant products. The FDAdefined remanufacturing is based on perceived operators' potential to alter the safety, performance and intended use of medical equipment instead of similarity of the involved process with the traditional remanufacturing process. On the other hand, the GRP refurbishment apparently exceeds the criteria for remanufacturability by providing various post-market services in addition to "as good as new" quality and warranty. Provision of post sales services is a potential solution to the main challenge faced by many developing countries in maintaining medical equipment. The selection of high performing equipment for GRP reduces the uncertainty in core quality while ensuring that the intended use of the equipment is not altered.

Remanufactured products are "as good as new" equivalents. This "as good as new" quality is proven by the provided warranty which at least, equals that of equivalent new equipment. For most products, such warranty sufficiently presents a remanufactured product as being of equal or better quality with equivalent new ones and so, boosts customers' confidence.

However, for medical equipment, warranty alone would not be sufficient since most manufacturers of new products also provide other professional post-sales services such as training, servicing and supply of spare parts in addition to warranty. To effectively argue that remanufactured equipment is as good as new equivalent, the remanufacturer should be able to provide these services. Besides, continued use of medical equipment may be impacted seriously by the unavailability of accessories. This is the case for developing countries.

GRP refurbishment already has this requirement as a criterion but is limited in scope as it was only proposed for imaging equipment. However, the practice provides the same assurance of quality and satisfaction to customers as they would derive from new products. The GRP guideline therefore presents the minimum requirements for medical equipment remanufacturing especially for developing countries. Accordingly, medical equipment remanufacturing may therefore be defined as follows: 
The industrial process by which a used equipment is restored to at least, original equipment manufacturer's performance and safety specifications from customers' and regulatory perspectives; with the resultant product capable of performing its intended use and given a warranty as well as provision for professional post-sales services that are at least as good as those given to an equivalent new one.

\section{Features of the proposed definition}

It is important to emphasise the clause: "restored at least, to Original Equipment Manufacturer (OEM) performance and safety specification." This implies that remanufactured medical equipment may either be upgraded or simply restored to the OEM specifications. Since new medical equipment are normally required to comply with appropriate regulations, it would be necessary to subject equipment claimed to have been upgraded in the process, to premarket evaluation to validate the claims. This is necessary as the upgrade may change the safety or performance specification originally intended by the manufacturers. Potential remanufacturers who do not claim to upgrade their products may only be required to validate their remanufacturing process and demonstrate compliance with the appropriate quality management system. Further a taskforce may be set up to enforce compliance.

The requirement for validating upgraded products would correspond to the FDA's current regulatory system concerning remanufacturing. In contrast to the FDA's position, the proposed approach to characterising medical equipment remanufacturing recognises that remanufacturing can be restorative as well as upgrading in nature and proposes subjecting only those equipment upgraded during remanufacture, to premarket qualification process. The qualification process would require the remanufacturer to demonstrate that the equipment still complies with relevant international standards. Figure 4 presents a flow diagram for medical equipment remanufacturing based on the proposed definition.

The inclusion of professional post-sales services distinguishes the proposed definition from the conventional definition of remanufacturing. Professional post-sales services such as provision of post sales technical support and supply of spare parts would assure customers that lack of spare parts cannot cause abrupt suspension of the product's utility. Therefore, the definition reflects the "crucial role of remanufacturing in the paradigm shift from mere product sales to the sales of services" [42]. This association between remanufacturing and servitisation which is extremely important for remanufactured medical equipment is not included as a requirement in the conventional definition.

Provision of post sales services by manufacturers usually gets them more involved the equipment lifecycle and offer them access to information to make improved product designs. Provision of post sales services by manufacturers engaging in remanufacture would thus, make it easier to keep up with post-sales requirements of medical device regulatory systems such as adverse effects reporting which includes reporting of serious injuries or death due to the use of the device. Finally, post-sales services can increase potential customers' confidence in remanufactured medical equipment as it would provide easy access to technical support.

In line with the conventional definition, remanufactured medical equipment would retain its intended use. The intended use has an impact on the class to which a medical device may be assigned [45]. Since remanufacturing aims to restore the equipment, it 


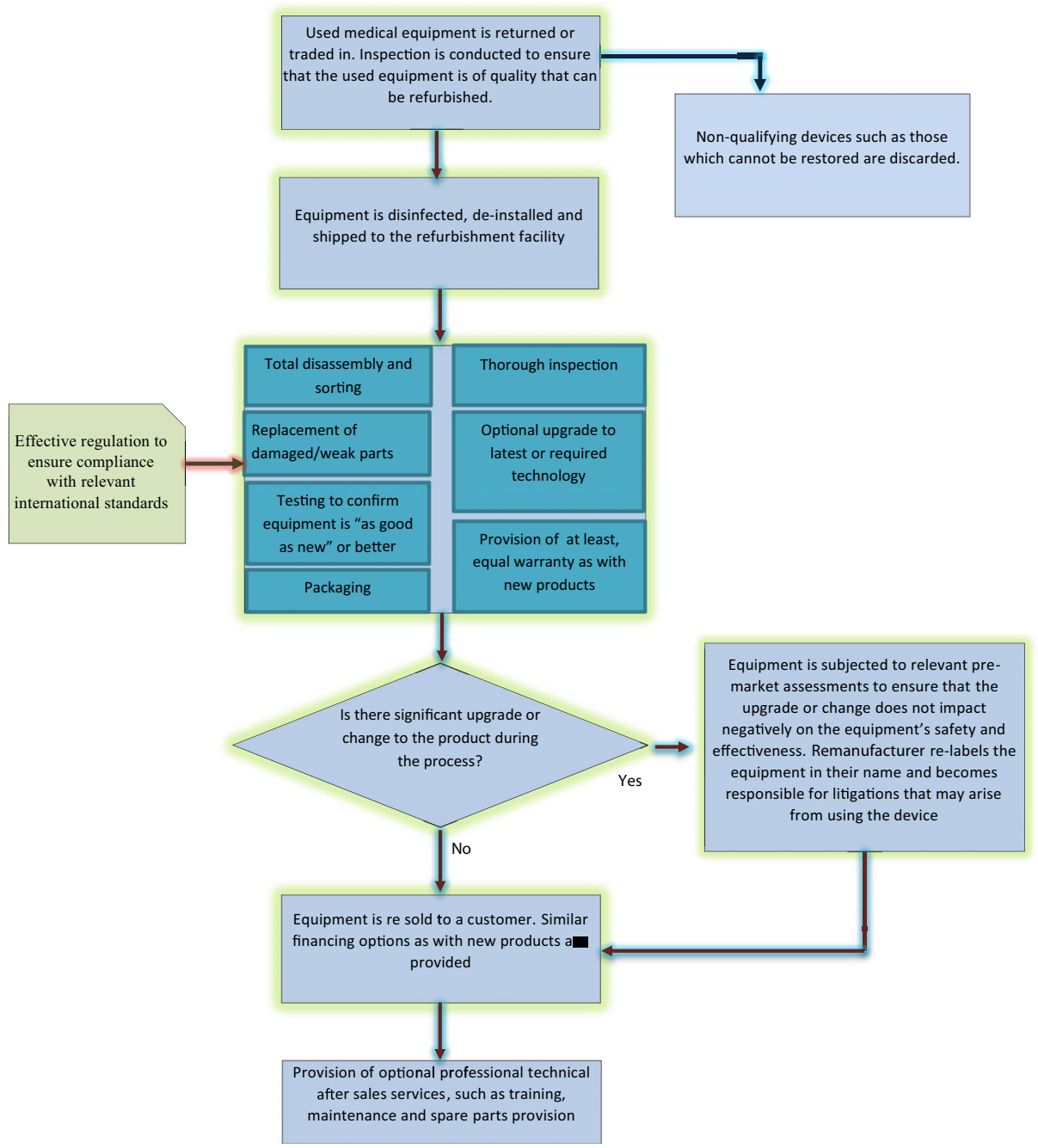

Fig. 4 Definitional block model for medical equipment remanufacturing. The diagram shows activities involved in medical equipment remanufacturing

should therefore not result in its reclassification. Hence, if a medical device is considered remanufacturable, then the resultant product should also retain the intended use of the original product. However, the process must guarantee that the resultant product would still be safe and effective. This rule would ordinarily imply that SUDs cannot be remanufactured.

However, from a slightly different perspective, a suitable constraint for considering the remanufacturability of SUDs may be that the resultant products still remain SUDs. For instance, Kodak remanufactures its single use cameras and markets the finished products as single use cameras. It is necessary to have a holistic decision-making framework to guide stakeholders in determining remanufacturable medical devices as well as to characterise the remanufacturing process. 


\section{Validation of proposed the model-based definition}

The proposed definitional framework was validated in two phases, by stakeholders purposively selected from developing countries. The participants have varying degrees of experience in fields that relate directly with developing countries' medical equipment; thus they have the necessary understanding of medical equipment needs of developing countries' health care as well as measures that can help to address them. The participants' opinions converged to inform the improvements that yielded the final model.

The first validation phase was inspired by two principal objectives. The first objective was to assess the relevance of medical equipment remanufacturing concept as proposed, in addressing the poor availability of medical equipment in developing countries. The second objective was to optimise the model and assess its practicability. The hypothetical framework shown in Appendix was the reference point of the validation process. In this phase, each of the participants summarised in Table 3 were sent an online link to the questionnaire in addition to a colourful copy of the framework. The term "refurbishment" was used in the questionnaire in order to clearly point out areas which the proposed medical equipment remanufacturing aims to enhance. The final copy of the framework shown on Fig. 4 was developed based on the participants' inputs as well as further interviews held with some of them concerning their inputs that required clarification.

\section{Phase 1 validation results}

Firstly, the participants were asked to indicate, using a scale of 1-10, how much they agreed that the framework represents the activities that are necessary to ensure that remanufactured medical equipment are of high quality. Based on their assessment, the average extent to which the framework represents necessary activities was 7.9 with a standard deviation of 2.0 or

Table 3 Characteristics of the participants in phase 1 of the validation process

\begin{tabular}{|c|c|c|c|c|}
\hline Respondents & Organisation & Country & Profession & $\begin{array}{l}\text { Years of } \\
\text { Experience }\end{array}$ \\
\hline A & Ministry of Health & Nigeria & Medical doctor & 7 \\
\hline B & Food and Drug Agency & Ghana & Biomedical Engineer & 14 \\
\hline $\mathrm{C}$ & Clinics service provider & Nigeria & Biomedical Technician & 5 \\
\hline $\mathrm{D}$ & $\begin{array}{l}\text { Industry and Tertiary education } \\
\text { institution }\end{array}$ & Nigeria & Biomedical Engineer & 25 \\
\hline $\mathrm{E}$ & Tertiary education institution & Nigeria & Medical Devices & 6 \\
\hline $\mathrm{F}$ & Tertiary education & Iraq & $\begin{array}{l}\text { Medical Instrumentation } \\
\text { technology }\end{array}$ & 2 \\
\hline G & Tertiary education institution & Malawi & Biomedical Engineer & 4 \\
\hline $\mathrm{H}$ & Medical centre & $\begin{array}{l}\text { Nigeria and } \\
\text { United Kingdom }\end{array}$ & $\begin{array}{l}\text { Medical Doctor } \\
\quad \text { (General practitioner) }\end{array}$ & 8 \\
\hline I & $\begin{array}{l}\text { Medical equipment sales and } \\
\text { servicing }\end{array}$ & Cameroun & Biomedical Engineer & 4 \\
\hline $\mathrm{J}$ & $\begin{array}{l}\text { University college hospital and } \\
\text { university of Ibadan }\end{array}$ & Nigeria & Medical Physicist & 22 \\
\hline $\mathrm{K}$ & $\begin{array}{l}\text { University college hospital, } \\
\text { Ibadan }\end{array}$ & Nigeria & Biomedical Engineer & 16 \\
\hline $\mathrm{L}$ & $\begin{array}{l}\text { Federal Institute of Industrial } \\
\text { Research }\end{array}$ & Nigeria & $\begin{array}{l}\text { Electromechanical } \\
\text { Engineer }\end{array}$ & 10 \\
\hline
\end{tabular}


simply $(7.9 \pm 2.0)$. The major concerns included that medical equipment refurbishment should comply with relevant regulatory standards and emphasis on quality control. The respondent that stressed quality control noted that mere replacement of damaged parts does not bring about product renewal as other parts may damage subsequently, when the device is put to use following refurbishment. In view of these observations, regulatory control was included in the framework. The regulatory control would ensure that the disassembly, inspection, testing, replacement of damaged and worn parts, optional upgrade and packaging complies with appropriate international standards. The provision of warranty and optional financing arrangements similar to those applied to equivalent new products included in the framework will also, further allay quality concerns.

The participants strongly opposed remanufacturing single use devices; noting that they cannot be restored to "as good as new" quality. The main reasons for their opposition were that SUDs are disposables and may not have been designed for remanufacture. The strength of their opposition was $8.2 \pm 2.4$. One of the participant's strength of opposition to the potential for restoring SUDs to as good as new quality was 3 . However, his reason which is that medical device class as well as regulatory requirements needs to be considered in selecting equipment to refurbish does not seem to agree with the extent he indicated.

The participants agreed strongly $(8.9 \pm 1.64)$ that refurbished equipment should be marketed with the same level of professional post sale technical support as with new equivalents but made optional. Their view on this are summarised in Table 4. One of the participants indicated lower value. The concern was that electronic products have specific lifetime which may necessitate replacing most components; thus making post sales technical service support difficult and expensive.

The participants also strongly agreed $(8.8 \pm 1.5)$ that refurbished equipment claimed to have been upgraded in the process should be subjected to pre-market evaluation for verification.

Table 4 Responses to the extent to which it is necessary to provide post sales technical support for refurbished medical equipment

Respondents Extent Rationale

\begin{tabular}{|c|c|c|}
\hline A & 10 & This will help prolong the period of use of the medical equipment \\
\hline B & 5 & $\begin{array}{l}\text { Electronic products have definite lifespan which may negate cost-effective provision of } \\
\text { post sales services }\end{array}$ \\
\hline $\mathrm{C}$ & 7 & Agree but should be made optional. \\
\hline $\mathrm{D}$ & 10 & $\begin{array}{l}\text { Post sales services would help remanufacturers to keep up with necessary regulatory } \\
\text { requirements. }\end{array}$ \\
\hline $\mathrm{E}$ & 9 & $\begin{array}{l}\text { Users will believe that servicing and post-sales services for a refurbished medical device } \\
\text { would be more rampant compared to a new equivalent. By agreeing to provide such } \\
\text { services, remanufacturers will allay their fears. }\end{array}$ \\
\hline $\mathrm{F}$ & 8 & $\begin{array}{l}\text { Post-sale technical support should be given more attention compared with new } \\
\text { equivalent. }\end{array}$ \\
\hline G & 10 & $\begin{array}{l}\text { This will validate the claim that the refurbishment has successfully restored the product to } \\
\text { as good as new quality }\end{array}$ \\
\hline $\mathrm{H}$ & 10 & $\begin{array}{l}\text { Ability to provide technical support is central to buyer confidence for remanufactured } \\
\text { products as the buyer knows that they can be assisted if machines ever fail }\end{array}$ \\
\hline I & 10 & To ensure that finished products are of high quality \\
\hline $\mathrm{J}$ & 10 & $\begin{array}{l}\text { Providing such services will be excellent in addressing the medical equipment needs of } \\
\text { the developing countries. }\end{array}$ \\
\hline K & 9 & $\begin{array}{l}\text { To ease maintenance and servicing of the equipment and to demonstrate the equipment is } \\
\text { equal to new equivalent in all respects }\end{array}$ \\
\hline & 9 & To sustain the remanufactured equipment \\
\hline
\end{tabular}


They stressed that the fact that medical equipment is said to be refurbished increases the need for pre-market verification and also points to the need for establishing an objective way of establishing that the claimed upgrade will not alter the safety and performance of the finished product.

\section{Phase 2 validation result}

The second phase of validation was carried out after optimising the model with inputs gathered from experts in phase 1. The process was carried out in the South Western Nigeria and involved the following:

- Chief Medical Director and top officers of the biomedical engineering unit in the top tertiary hospital located in the region.

- A senior medical officer in a major privately managed hospital in the region.

All respondents strongly acknowledged that the remanufacturing process as represented in the block model was clear and can bring about a sustainable solution to medical equipment supply in developing countries.

\section{Potential considerations in implementing medical equipment remanufacturing in developing countries from resource-based-view perspective}

The degradation state or quality of returned end-of-life products is an essential factor in the decision-making preceding remanufacturing. Used medical equipment selected for remanufacture must be those that have only sustained minimal or recoverable degradation. If usage and failure data are available, then the residual quality of the recovered end-of-life equipment may be estimated. For the more complex equipment, this may be accomplished by analysing maintenance record. For instance, a plot of the number of failures against times-to-failure can indicate the health of the equipment [46]. A linear profile would show that the inter-occurrence times of failures still have the same length in terms of time. Such an outcome may justify the selecting the equipment for remanufacture. It is also possible to apply condition monitoring techniques and use suitable models such as Proportional Hazard; to determine the residual quality of returned equipment [47].

The medical equipment being selected must be those that contribute to existing healthcare needs and/or which can be integrated into existing clinical practices. Thus, a prior needs assessment is vital in deciding which medical equipment to remanufacture. Equipment with existing health care needs would have higher market potential and would have the potential to compete favourably in the market when remanufactured. One way of performing needs assessment is by developing a database of most incident healthcare problems [48].

Other factors to consider in implementing medical equipment remanufacturing include legislative factors, economic factors, technological factors, logistic factors and market-related factors. These factors may not be independent; for instance, elements of economic consideration must be present in each factor to ensure profitability. It is imperative to consider prevailing legislations relating to remanufacturing especially the requirements of medical equipment regulations since it would be impossible to market finished products if they do 
not comply with them. Potential remanufacturers must therefore develop the capability to ensure that finished products comply with all relevant standards. It is also vital to consider legislation relating to importation since cores or replacement parts may have to be imported to facilitate remanufacturing enterprise business. Import restrictions are detrimental to remanufacturing.

Technological factors include ease of disassembly and handling, ease of inspection and testing, ease of cleaning, ease of disinfection and/or sterilisation, upgradeability to the latest or appropriate technology and recoverability of components. These factors dictate the degree to which used medical equipment returned for remanufacture can be safely remanufactured. Among other factors, product design plays a key role in this consideration. Remanufacturers must also have the skills to conduct failure diagnoses, deal with returns of varying degrees of quality, recover those components that can be safely recovered and test the finished products to ensure they have been truly restored to at least, an as good as new condition.

Technological considerations also include cleaning and disinfection for equipment such as chemistry analysers and those that contact tissues and body fluids. The ease of cleaning should assess how effective cleaning can be achieved without removing the OEM's markings or labels on the equipment [49], especially those that can impact the use of the equipment. The ease of disinfection on the other hand, should evaluate how feasible it would be to achieve the required level of disinfection. Disinfection can be low level, high level or sterilisation according to whether the equipment or module is critical, semi-critical or non-critical. Critical equipment or modules are those that enter sterile tissues including vascular system; semicritical equipment or module contact non-intact skin or mucous membranes but do not penetrate them while non-critical equipment directly contacts the intact skin. Sterilisation is the highest level of disinfection which aims at killing all the microorganisms present in a component using physical, chemical or physiochemical means. Depending on the appropriate level of disinfection, the assessment of ease of disinfection should consider geometrical shape, material properties and the properties of the disinfecting agent. This is because the presence of long, narrow lumens for instance, would make the passage of disinfectants difficult. In addition, rough surfaces can reduce the efficiency of disinfection by providing safe sites for microbes. Similarly, material damage caused by disinfecting agents may vary with the chemical structure of the material of which the equipment or module is made. Developing technological capability is thus, very crucial to the implementation of medical equipment remanufacturing.

Medical equipment may have to be upgraded to the latest technology or appropriate technology during remanufacturing. Such an upgrade may involve replacement of hardware components or software upgrade. For instance, an appropriate upgrade for medical equipment being remanufactured for developing country may be to adapt them to the voltage of the national grid. From this perspective, remanufacturing may be useful in ratifying medical equipment donation to developing countries as equipment coming from various sources would be adapted to the mains supply of the destination countries.

Since manufacturers get involved in the medical equipment market, remanufacturers should also do the same to demonstrate that their products are equally competitive. Thus, a remanufacturer may first assess the potential demand and acceptability of their products to determine their market potentials. The remanufacturer may also have to 
develop channels or framework to market its products and to fulfill relevant post-sales responsibilities.

\section{Recommendations to facilitate medical equipment remanufacturing for developing countries}

Developing countries need to create or awaken their regulatory authorities to ensure that remanufactured medical equipment would be safe and effective. While regulation is important in ensuring this, extreme regulatory restrictions would hamper the success of remanufacturing. Regulations may focus on ensuring that appropriate quality management system is put in place by potential remanufacturers. Remanufactured medical equipment claimed to have been upgraded in terms of performance or safety should be subjected to premarket tests as shown in Fig. 4, to validate the upgrade. The premarket validation processes should however, not be made too complicated or expensive for potential remanufacturers to avoid making such ventures unattractive. It would therefore be essential to create an enabling environment for potential remanufacturers.

Some of the recommendations to achieve necessary environment for potential remanufacturers include the following:

1. Create opportunities for economy of scale advantage for reputable manufacturers. By attracting reputable manufacturers to a nation's medical equipment market, it would be easier to provide support to the industry in terms of design information and spare parts supply. This may be realised through the formulation of robust health technology assessment (HTA) and health technology management (HTM) emphasising the need to reduce diversification of product models while increasing patronage for manufacturers that are willing to support remanufacturing.

2. Provide incentives such as tax relaxations for prospective remanufacturers. It is the government's responsibility to ensure that healthcare is affordable to its people. Remanufacturers of medical equipment would be assisting the government in this role and should be assisted by the government. One of the most typical ways in which governments support industries through their growth period is by providing tax holidays. Incentives can help potential remanufacturers to focus on investments that are related to the business rather than with payment of tax.

3. Make policies to diminish the "as is" used medical equipment market. Although "as is" used medical equipment may be considerably cheap to purchase, their quality cannot be guaranteed and supply of spare parts and consumables may become unavailable. Unfortunately, "as is" used medical equipment are widely used in developing countries, contributing significantly to a large number of non-functioning medical equipment in the countries. Given the associated futility, some developing countries have already banned the importation of "as is" used medical equipment out rightly, while about seventeen others are considering banning it. These measures would however, hamper remanufacturing. Governments may on the other hand, allow only licensed remanufacturers to import used equipment which serves as the core and remanufacture them before selling them in the local market. 
4. Raising remanufacturing awareness in healthcare institutions so that they may take advantage of the benefits of remanufactured medical equipment to improve their healthcare delivery. Remanufacturing is a new concept in many developing countries. Consumers' perception of remanufactured products as inferior has already been variously reported in the literature. Such perceptions may be more pronounced for remanufactured medical equipment due to the critical roles that they play in the healthcare. Governments should first ensure adequate regulatory oversight for remanufacturing activities and then encourage health care institutions and professionals to purchase remanufactured medical equipment. This would contribute towards expanding the market and also serve as an incentive for potential remanufacturers.

5. Making HTA and HTM policies that facilitate the procurement of medical equipment designed to ease remanufacturing. HTA ensures that procured equipment would satisfy a therapeutic need more efficiently and economically than extant options. Effectiveness refers to the ability of an equipment to satisfactorily perform the tasks for which it is procured while economic consideration is about cost justification. Conventional HTA and HTM only consider disposal after the "use" phase of medical equipment, precluding remanufacturing. To take advantage of remanufacturing, health technology experts have to consider the remanufacturabiliity of medical equipment being considered for procurement. Such a practice will extend the horizon over which economic benefits would be realised from the equipment. Key factors to consider include the modularity of the design which influences the ease of disassembly and reassembly, durability of key parts, ease of inspection, upgrade, cleaning, and decontamination as well as recoverability of key parts.

6. Governments may relax regulations such as the RoHS and recommendations of the Basel Convention on transboundary movement of used hazardous products which would adversely affect both the market for remanufactured products and the sourcing of cores. The RoHS Directive would not allow marketing of remanufactured medical equipment now classified as hazardous products while the Basel agreement would prohibit the importation of used products which is critical to the success of remanufacturing. Governments may, however, limit the import licence of used medical equipment and sales of remanufactured ones to accredited remanufacturers. This would serve as a measure to deter abuse and hence reduce the potential for dumping of unviable used products in developing countries. Medical equipment remanufactured according to the proposed definition should also, be regarded as new since it would offer all the benefits that ordinarily accompany new equivalents including the provision of post sales services which can serve as a proof of the remanufacturer's commitment to supplying only highquality products.

7. Governments may introduce the teaching of remanufacturing to Biomedical engineering students since they are being trained in medical equipment design, manufacturing and maintenance. Biomedical engineers are usually members of HTA team. Therefore, including remanufacturing in biomedical education would increase remanufacturing skills and awareness and also create more opportunities towards formalising the use of remanufactured medical equipment. 
8. Reduce cost and unnecessary delays in fulfilling regulatory requirements. This may be achieved by formulating standard operational procedure for remanufacturers. By easing the process, through standardisation, the delay and cost may be reduced significantly. Also, it would be appropriate to ensure that potential remanufacturers put in place appropriate quality management system at the onset of the business. This would potentially reduce the roles of medical equipment market regulators in ensuring that remanufactured products are of acceptable quality.

9. Intellectual property and patent rights should be managed in such a manner as to support remanufacturing. A typical instance is the US Supreme court's ruling that patent right exhausts following a sale irrespective of manufacturer's express restrictions on resale or re-use [50]. Such rulings will give potential remanufacturers the freedom to develop remanufacturing technology for any medical equipment that satisfies their evaluation criteria.

10. Making laws that require manufacturers of medical equipment to disclose information relating to their products to enhance the remanufacturability. This is already the practice in the U.S where manufacturers of X-ray equipment are to release at a cost, not beyond the cost of publication and dissemination, information regarding the assembly, installation, adjustment and testing of their products (21 Code of Federal Regulations sec. 1020.30(g) [51]. Availability of such information will not only ease the remanufacturing process but provide the information needed to ensure that remanufactured products attain original equipment manufacturers specifications of safety and effectiveness.

\section{Conclusion}

Remanufacturing is a key sustainability strategy with only little uptake in many developing countries. The medical equipment sector is one crucial area where its practice would yield tremendous benefits contributing to the sustainable development goals of health and poverty alleviation. Since medical equipment plays a critical role in healthcare which necessitates their stiff regulation, it became crucial to review the regulatory oversight of medical equipment remanufacturing and related activities in the US and EU since regulation is usually inexistent or weak in developing countries. This paper shows that the definitions provided by the regulatory bodies in these countries do not correlate with the basic principles of remanufacturing and provide no guide for potential remanufacturers. This lack of precise definition would demand an intense investigation and monitoring of operators and may complicate the accreditation process for potential remanufacturers. This paper, therefore, proposed and validated a working definition for medical equipment remanufacturing which can potentially facilitate medical equipment availability in developing and other interested developed countries if the recommendations presented are implemented. The definition would ensure that remanufacturers sustainably deliver quality medical equipment. Further research may look into the development of decision-making tools for selecting medical equipment for remanufacture. Remanufacturability studies of specific medical equipment would also be exciting areas for future research. 


\section{Appendix}

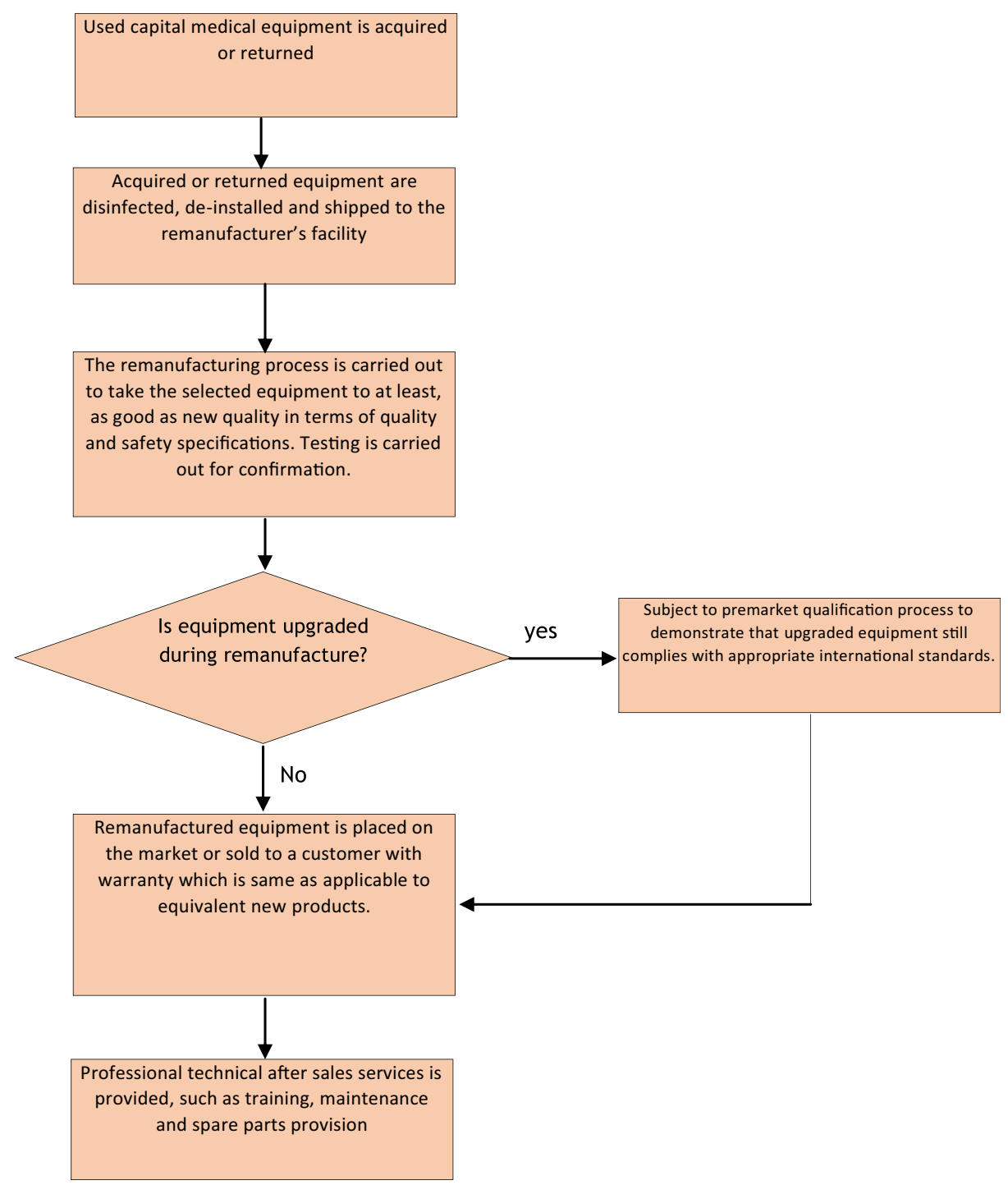

Fig. 5 Initial framework which served as reference to the refined model

The model represented here was based on the the initial definition of remanufacture as: The industrial process by which a used equipment is restored to at least, original equipment manufacturer's performance and safety specifications from customer's perspective; with the resultant product capable of performing its intended use and given a warranty as well as provision for professional post-sales services that are at least as good as those given to an equivalent new one. 
Open Access This article is distributed under the terms of the Creative Commons Attribution 4.0 International License (http://creativecommons.org/licenses/by/4.0/), which permits unrestricted use, distribution, and reproduction in any medium, provided you give appropriate credit to the original author(s) and the source, provide a link to the Creative Commons license, and indicate if changes were made.

Publisher's Note Springer Nature remains neutral with regard to jurisdictional claims in published maps and institutional affiliations.

\section{References}

1. WHO (2017) The top 10 causes of death in 2015. WHO. World Health Organization

2. Mateosian R (2001) Making it work: a tool kit for medical equipment donations to low resource settings. Micro, IEEE 21:70-71

3. WHO. Barriers to Innovation in the Field of Medical Devices: Background Paper 06, August 2010 [Internet]. 2010 [cited 2017 May 11]. Available from: http://apps.who.int/medicinedocs/en/d/Js17701en/

4. Perry L, Malkin R. Effectiveness of medical equipment donations to improve health systems: how much medical equipment is broken in the developing world? Med Biol Eng Comput [Internet]. 2011 Jul 20 [cited 2017 may 11];49(7):719-722. Available from: http://www.ncbi.nlm.nih.gov/pubmed/21597999

5. Cheng M, World Health Organization. Medical device regulations : global overview and guiding principles. [Internet] World Health Organization; 2003 [cited 2017 Jun 16]. 43 p. Available from: https:/books.google.co.uk/books?hl=en\&lr= \&id=zlY0DgAAQBAJ\&oi=fnd\&pg=PR3\&dq=good+manufacturing+practice+for+medical+device+refurbishe\&ots= VAJRuWohoz\&sig=IEinU_qTC0UMyBUiNPxm5xH9wpk\#v=onepage\&q\&f=false

6. Eltringham R, Neighbour R. The reality of designing appropriate 'low cost' medical products for developing countries and their unintended consequences. In: Appropriate Healthcare Technologies for Low Resource Settings (AHT 2014) [Internet]. Institution of Engineering and Technology; 2014 [cited 2017 May 11]. p. $32-$ 32. Available from: http://digital-library.theiet.org/content/conferences/10.1049/cp.2014.0792

7. Nimunkar AJ, Baran J, Van Sickle D, Pagidimarry NK, Webster JG. Medical devices for developing countries: Design constraints and approaches. In: 2009 Annual International Conference of the IEEE Engineering in Medicine and Biology Society [Internet]. IEEE; 2009 [cited 2017 Feb 19]. p. 7048-7051. Available from: http://ieeexplore.ieee.org/document/5333377/

8. Bracale M, Pepino A (1994) Medical technologies in developing countries: a feasibility study on the maintenance of medical equipment in Ethiopia. Med Biol Eng Comput 32(2):131-137

9. Lustick DR, Zaman MH (2011) Biomedical engineering education and practice challenges and opportunities in improving health in developing countries. In: 2011 Atlanta Conference on Science and Innovation Policy. IEEE, pp 1-5

10. Malkin R, Anand V (2010 Mar) A novel phototherapy device. IEEE Eng Med Biol Mag 29(2):37-43

11. Shah SGS, Robinson I, AlShawi S (2009) Developing medical device technologies from users' perspectives: a theoretical framework for involving users in the development process. Int $\mathbf{J}$ Technol Assess Health Care 25(4):514-521

12. Santos IC, Gazelle GS, Rocha LA, Tavares JMR. Medical device specificities: opportunities for a dedicated product development methodology. Expert Rev Med Devices [Internet]. 2012 May 9 [cited 2018 Feb 23];9(3):299-311. Available from: http://www.tandfonline.com/doi/full/10.1586/erd.12.3

13. Kapoor A, Vora A, Nataraj G, Mishra S, Kerkar P, Manjunath CN. Guidance on reuse of cardio-vascular catheters and devices in India: A consensus document. Indian Heart J [Internet]. 2017 May 1 [cited 2017 Nov 8];69(3):357-363. Available from: http://www.sciencedirect.com/science/article/pii/S001948321730247X

14. D'Adamo I, Rosa P. Remanufacturing in industry: advices from the field. Int J Adv Manuf Technol [Internet]. 2016 Oct 28 [cited 2017 Jun 9];86(9-12):2575-2584. Available from: http://link.springer. com/10.1007/s00170-016-8346-5

15. Widera H, Seliger G (2015) Methodology for exploiting potentials of remanufacturing by reducing complexity for original equipment manufacturers. CIRP Ann - Manuf Technol 64(1):463-466

16. Shi L, Ma X. Strategy analysis of closed loop supply chain for scrapped medical equipment based on hybrid recycling model. Adv Mater Res [Internet]. 2011 May [cited 2017 Jun 9];219-220:722-6. Available from: http://www.scientific.net/AMR.219-220.722

17. Sloan TW, Sloan TW (2007) Safety-cost trade-offs in medical device reuse: a Markov decision process model. Heal Care Manag Sci [Internet] 10:81-93

18. Parker D, Riley K, Robinson S, Symington H, Hollins O (2015) Remanufacturing market study. Eur Remanufacturing Netw 645984

19. Gray C, Charter M. Remanufacturing and product design - designing for the 7th generation. 2007; 
20. Hammond R, Amezquita T, Bras B (1998) Issues in the automotive parts remanufacturing industry - a discussion of results from surveys performed among remanufacturers. Int J Eng Des Autom - Spec Issue Environ Conscious Des Manuf 4(1):27-46

21. Ijomah WL, Childe S, Mcmahon C. Remanufacturing: A Key Strategy for Sustainable Development. In 2004 [cited 2016 Oct 20]. Available from: http://eprints.cdlr.strath.ac.uk/5505/

22. Paterson DAP, Ijomah WL, Windmill JFC. End-of-life decision tool with emphasis on remanufacturing. J Clean Prod [Internet]. 2017 [cited 2017 Jun 9];148:653-664. Available from: http:/www.sciencedirect. com/science/article/pii/S0959652617302159

23. Robert T. Lund. Remanufacturing : the experience of the United States and implications for developing countries (English) | the World Bank [internet]. World Bank, Washington DC; 1984 [cited 2017 May 11]. Available from: http://documents.worldbank.org/curated/en/792491468142480141/Remanufacturing-theexperience-of-the-United-States-and-implications-for-developing-countries

24. Coordination of notified bodies medical devices on 93/42/EEC and 98/79/EC. Placing on the market of full refurbished medical devices. 2000 [cited 2017 Apr 13];12(12). Available from: https://www.mdc-ce. de/fileadmin/user_upload/Downloads/Leitlinien/NB-Med/Recommendation-NB-MED-2_1-5_rev5 Placing on the market of fully refurbished medical devices.pdf

25. USITC (2012) Remanufactured Goods: An Overview of the U.S. and Global Industries, Markets and Trade [Internet]. United States International Trade Commission Available from: http:/www.usitc. gov/publications/332/pub4356.pdf

26. Fargen Kyle, Frei D, Fiorella David, McDoughall Cameron, Myers Philip, Hirsch James. FDA Approval Process for Medical Devices [Internet]. 2013 [cited 2017 Apr 25]. Available from: http://www.medscape. com/viewarticle/807243_2

27. van der Laan E, Salomon M, Dekker R, Van Wassenhove L. Drugs and Devices: Comparison of European and U.S. Approval Processes. Manage Sci [Internet]. 1999 May [cited 2017 Jun 3];45(5):733-747. Available from: http://pubsonline.informs.org/doi/abs/10.1287/mnsc.45.5.733

28. Parkinson HJ, Thompson G. Analysis and taxonomy of remanufacturing industry practice. Proc Inst Mech Eng Part E J Process Mech Eng [Internet]. 2003 Jan 1 [cited 2017 Jun 9];217(3):243-256. Available from: http://sdj.sagepub.com/lookup/10.1243/095440803322328890

29. MHRA. Single-use medical devices: UK guidance on re-manufacturing. 2016;

30. Tessarolo F, Ferrari P, Silvia B, Motta A, Migliaresi C, Zennaro L, et al. Evaluation and quantification of reprocessing modification in single-use devices in interventional cardiology. In: Applied Surface Science [Internet]. North-Holland; 2004 [cited 2017 Nov 14]. p. 341-346. Available from: http://www.sciencedirect. com/science/article/pii/S0169433204008955

31. Lee DH, Kim D Bin, Kim HY, Baek HS, Kwon SY, Lee MH, et al. Increasing potential risks of contamination from repetitive use of endoscope. Am J Infect Control [Internet]. 2015 May 1 [cited 2017 Nov 14];43(5):e13e17. Available from: http://www.sciencedirect.com/science/article/pii/S0196655315000358?via\%3Dihub

32. Smith JJ, Agraz JA. Federal regulation of singlue-use medical devices: a revised fda policy. Food Drug Law J [Internet]. 2001 [cited 2017 May 8];56. Available from: http://heinonline.org/HOL/Page?handle=hein. journals $/$ foodlj56\&id $=325 \&$ div $=32 \&$ collection=journals

33. Popp W, Rasslan O, Unahalekhaka A, Brenner P, Fischnaller E, Fathy M, Goldman C., Gillespie E. What is the use? An international look at reuse of single-use medical devices. Int J Hyg Environ Health [Internet]. 2010 Jul 1 [cited 2017 Nov 14];213(4):302-307. Available from: http://www.sciencedirect. com/science/article/pii/S1438463910000441

34. Shuman EK, Chenoweth CE. Reuse of Medical Devices: Implications for Infection Control [Internet]. Vol. 26, Infectious Disease Clinics of North America. Elsevier; 2012 [cited 2017 Nov 14]. p. 165-172. Available from: http://www.sciencedirect.com/science/article/pii/S0891552011000857?via\%3Dihub

35. Collier R. The ethics of reusing single-use devices. CMAJ [Internet]. 2011 Aug 9 [cited 2017 Nov 15];183(11):1245. Available from: http://www.ncbi.nlm.nih.gov/pubmed/21746819

36. Unger S, Landis A. Assessing the environmental, human health, and economic impacts of reprocessed medical devices in a Phoenix hospital's supply chain. J Clean Prod [Internet]. 2016 Jan 20 [cited 2017 Nov 14];112: 1995-2003. Available from: http://www.sciencedirect.com/science/article/pii/S0959652615010756

37. Smith JJ, Agraz JA. Federal regulation of singlue-use medical devices: a revised fda policy. Food Drug Law J [Internet]. 2001 [cited 2017 Nov 14];56. Available from: http://heinonline.org/HOL/Page?handle=hein. journals/foodlj56\&id=325\&div=32\&collection=journals

38. Vukelich D. Good as New: Reprocessing single-use devices [Internet]. 2016 [cited 2017 Nov 14]. Available from: http://www.medicaldevice-developments.com/features/featuregood-as-new\%2D\%2D-reprocessingsingle-use-devices-5663983/

39. Centre for Devices and Radiological Health. Quality Systems Regulation - Medical Devices; Current Good Manufacturing Practice (CGMP) Final Rule. 1996 [cited 2017 Jun 16]; Available from: https://www.fda. 
gov/MedicalDevices/DeviceRegulationandGuidance/PostmarketRequirements/QualitySystemsRegulations/ ucm230127.htm

40. Guide VDR, Jayaraman V, Srivastava R (1999 Jun) Production planning and control for remanufacturing: a state-of-the-art survey. Robot Comput Integr Manuf 15(3):221-230

41. Ijomah WL, McMahon CA, Hammond GP, Newman ST (2007) Development of design for remanufacturing guidelines to support sustainable manufacturing. Robot Comput Integr Manuf 23(6):712-719

42. Ijomah WL. Addressing decision making for remanufacturing operations and design-for-remanufacture. Int J Sustain Eng [Internet]. 2009 Jun [cited 2017 May 11];2(2):91-102. Available from: http://www. tandfonline.com/doi/abs/10.1080/19397030902953080

43. Plumeyer M, Braun M. Medical Electrical Equipment - Good Refurbishment Practice at Siemens AG Healthcare. In: Glocalized Solutions for Sustainability in Manufacturing [Internet]. Berlin: Springer Berlin Heidelberg; 2011 [cited 2017 Apr 11]. p. 497-500. Available from: http://link.springer.com/10.1007/978-3642-19692-8_86

44. COCIR. Good refurbishment practice. 2007 [cited 2017 Apr 11]; Available from: http://www.cocir. org/fileadmin/6.1_Initiatives_Refurbishment/Good_Refurbishment_Practice_V2.pdf

45. European Commission DG Health and Consumer. Guidelines relating to the application of the council Directive 93/42/EEC on medical devices. 2010 [cited 2017 Jun 19]; Available from: http://ec.europa. eu/consumers/sectors/medical-devices/files/meddev/2_4_1_rev_9_classification_en.pdf

46. Marvin R, Arnljot H (2004) System reliability theory: models, statistical methods and applications. In: Balding JD, Cressie ACN, Fisher IN, Johnston MI, Kadane J, Molengurghs G et al (eds), 2nd edn

47. Meng K, Lou P, Peng X, Prybutok V (2017 Aug) Quality-driven recovery decisions for used components in reverse logistics. Int J Prod Res 55(16):4712-4728

48. WHO (2010) Medical devices: Managing the mismatch barriers to innovation in the field of medical devices. World Heath Organization

49. Hundal M (2000) Design for recycling and remanufacturing. In: Marjanovic D (ed) Proceedings of the 6th international design conference: design 2000, pp 165-170

50. Supreme court of the United States. Impression Products Inc. vs Lexmark International Inc. [Internet]. 2017 [cited 2017 Jun 15]. Available from: https://www.supremecourt.gov/opinions/16pdf/15-1189_ebfj.pdf

51. Guidance for Industry and FDA Staff Information Disclosure by Manufacturers to Assemblers for Diagnostic X-ray Systems Additional Copies. 2003 [cited 2017 Jun 16]; Available from: http://www.fda. gov/dockets/ecomments 